\title{
ChemComm
}

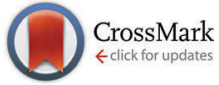

Cite this: Chem. Commun., 2015, 51, 13036

Received 11th June 2015, Accepted 10th July 2015

DOI: $10.1039 / \mathrm{c} 5 \mathrm{cc} 04850 \mathrm{~h}$

www.rsc.org/chemcomm

\section{New AIE-active dinuclear Ir(III) complexes with reversible piezochromic phosphorescence behaviour}

\author{
Guangfu Li, ${ }^{a}$ Xinyao Ren, ${ }^{a}$ Guogang Shan, ${ }^{a}$ Weilong Che, ${ }^{a}$ Dongxia Zhu, ${ }^{a}$ \\ Likai Yan, ${ }^{a}$ Zhongmin Su*a and Martin R. Bryce*b
}

Two new AIE-active dinuclear Schiff base Ir(III) complexes exhibit highly reversible piezochromic phosphorescence behaviour enabling the construction of a re-writable phosphorescence data recording device.

Phosphorescent transition metal complexes are widely exploited in various optoelectronic applications due to their rich excitedstate properties, such as high luminescence quantum yields, long emission lifetimes, large Stokes shifts and high photo-stability compared to fluorescent dyes. ${ }^{1}$ However, there have been only limited studies focusing on the switching range of the phosphorescence emission of such materials in response to stimuli and their potential applications such as data recording and storage. Piezochromic materials, the emissions of which can be repeatedly switched between different colours under external pressure or mechanical grinding, have received considerable attention in the construction of optical data recording and storage devices. ${ }^{2}$ Recently, a series of organic small-molecules, metal complexes, liquid crystalline materials, polymers and metal-organic frameworks with intriguing piezochromic properties have been investigated. ${ }^{3}$ However, piezochromic phosphorescence has only rarely been observed in transition metal complexes and the relationship between changes in molecular assembly and their luminescence properties are not well understood. Moreover, similar to most conventional dyes, transition metal complexes usually suffer from low luminescence efficiency in the solid or aggregated state, due to aggregation-caused quenching (ACQ). ${ }^{4}$ This drawback in piezochromic materials significantly limits the real-world applications of these luminophores.

\footnotetext{
${ }^{a}$ Institute of Functional Material Chemistry, Faculty of Chemistry,

Northeast Normal University, Renmin Road 5268, Changchun 130024,

P. R. China.E-mail:zhudx047@nenu.edu.cn,zmsu@nenu.edu.cn

${ }^{b}$ Department of Chemistry, Durham University, Durham, DH1 3LE, UK.

E-mail:m.r.bryce@durham.ac.uk

$\dagger$ Electronic supplementary information (ESI) available: Experimental details, figures and procedures for the DFT calculations. CCDC 1046679. For ESI and crystallographic data in CIF or other electronic format see DOI: $10.1039 / \mathrm{c} 5 \mathrm{cc} 04850 \mathrm{~h}$
}

Aggregation-induced emission (AIE) in the solid or aggregated state, which is the opposite of ACQ, was first reported by Tang et al. in $2001 .^{5}$ Recently, a number of pure organic fluorescent small molecules have been shown to simultaneously exhibit AIE and piezochromism. ${ }^{6}$ Very recently, Chi $e t$ al. proved that the positive effect of AIE on luminescence enhancement may provide a direction for the development of more efficient piezochromic materials. ${ }^{7}$ Therefore, AIE materials may become important alternative sources of piezochromic materials. However, phosphorescent luminophores with these dual properties are largely unexplored. Previous reports have focused on charged monoiridium complexes with dendrimer-like or flexible alkyl chain substituents which exhibit piezochromism. ${ }^{8}$

Schiff base ligands play an important role in metal coordination chemistry, even after almost a century since their discovery, due to their facile synthesis, remarkable versatility and good solubility in common solvents. ${ }^{9}$ In general, compared with rigid ligands, a metal-coordinated Schiff base ligand can readily form intermolecular $\pi-\pi$ or $\mathrm{C}-\mathrm{H} \cdots \pi$ interactions in the aggregated or crystal state because of the high flexibility of the imine unit. However, this structural flexibility can also induce relatively loose molecular packing, which might be easily collapsed by external pressure with a resulting effect on the HOMO-LUMO energy levels which would alter the luminescent properties. ${ }^{10}$ Thus, it is of interest to ask: "What will happen when Schiff base complexes are stimulated by external pressure?" Therefore, the development of a new class of Schiff base piezochromic materials with high luminescent efficiency is of fundamental importance in exploring the relationship between solid state structure and luminescence.

Inspired by this idea, herein, we describe two new dinuclear cationic $\operatorname{Ir}(\mathrm{III})$ complexes, $\left[(2 \mathrm{~F}-\mathrm{ppz})_{2} \operatorname{Ir}-(\mathrm{L} 1)-\operatorname{Ir}(2 \mathrm{~F}-\mathrm{ppz})_{2}\right]\left[\mathrm{PF}_{6}\right]_{2}(\mathbf{1})$ and $\left[(2 \mathrm{~F}-\mathrm{ppz})_{2} \mathrm{Ir}-(\mathrm{L} 2)-\operatorname{Ir}(2 \mathrm{~F}-\mathrm{ppz})_{2}\right]\left[\mathrm{PF}_{6}\right]_{2}$ (2) with Schiff base bridging ligands (L1) and (L2), respectively (Scheme 1). Their ${ }^{1} \mathrm{H}$ NMR spectra, photophysical properties, powder X-ray diffraction, single-crystal X-ray structure (for 1) and differential scanning calorimetric (DSC) data are presented. The results obtained demonstrate that both complexes $\mathbf{1}$ and $\mathbf{2}$ are AIE-active and simultaneously show piezochromism and vapochromic 


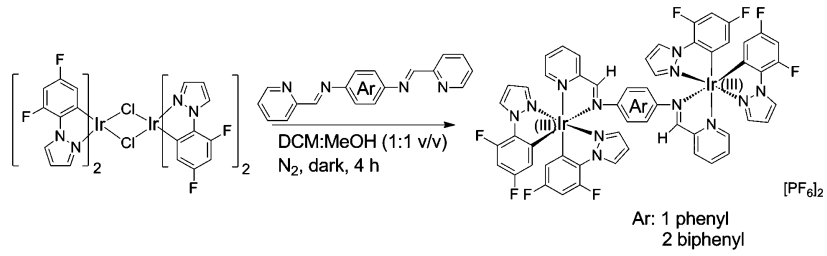

Scheme 1 Chemical structures of the complexes, with bridging phenyl (1) and $4,4^{\prime}$-biphenyl (2) units.

phosphorescence. We conclude that the flexible bridging ligands play a significant role in achieving these combined properties. Most importantly, the highly reversible piezochromic behaviour makes both complexes competitive candidates for practical applications. Indeed, we have shown that complex 2 provides a fast-responding re-writable phosphorescence data recording device.

The UV/vis absorption and emission spectra of complexes $\mathbf{1}$ and 2 in degassed solution $\left(\mathrm{CH}_{3} \mathrm{CN}\right)$ are depicted in Fig. 1a. Upon photoexcitation, complexes $\mathbf{1}$ and $\mathbf{2}$ are almost non-emissive in pure $\mathrm{CH}_{3} \mathrm{CN}$ solution. However, the powdered samples of $\mathbf{1}$ and $\mathbf{2}$ exhibit intense phosphorescence at room temperature, with $\Phi_{\mathrm{em}}$ 0.31 and 0.24 , respectively (Table S1, ESI $\dagger$ ). Such strong luminescence in the solid state is a requirement for luminescence switching in experiments of piezochromic behaviour (see below).

To probe the AIE of complexes $\mathbf{1}$ and $\mathbf{2}$, their photoluminescence (PL) spectra in $\mathrm{CH}_{3} \mathrm{CN}-\mathrm{H}_{2} \mathrm{O}$ mixtures with various water contents were obtained (Fig. $1 \mathrm{~b}$ and Fig. S1, ESI $\dagger$ ). The phosphorescence intensity of both complexes is dramatically enhanced when the water fraction reached $60 \%$. Furthermore, transmission electron microscopy (TEM) and electron diffraction (ED) experiments indicated that amorphous molecular aggregates are formed in the mixtures (Fig. S2, ESI $\dagger$ ). ${ }^{8 a}$ The results confirm that complexes $\mathbf{1}$ and $\mathbf{2}$ are AIE active. To gain further understanding of the unusual solid-state emission properties, the geometry of complex 1 was optimized by referring to the $\mathrm{X}$-ray diffraction data, and the electronic properties of the frontier orbitals were studied in the solution and the solid state structures using density functional theory (DFT) methods (Fig. 2).

In the solution state of complex $\mathbf{1}$, both the highest occupied molecular orbital (HOMO) and the lowest unoccupied molecular

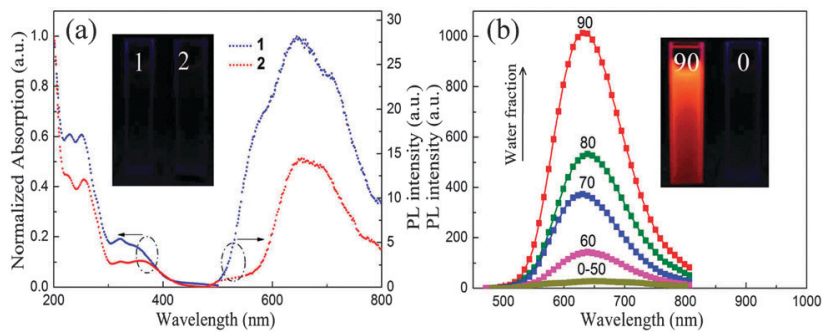

Fig. 1 (a) Absorption and emission spectra of complexes 1 and 2 in acetonitrile solution at room temperature. Inset: emission image of complexes $\mathbf{1}$ and $\mathbf{2}$ in pure acetonitrile solution under $365 \mathrm{~nm}$ UV illumination; (b) emission spectra of complex 1 in $\mathrm{CH}_{3} \mathrm{CN}$-water mixtures with different water fractions $(0-90 \% \mathrm{v} / \mathrm{v})$ at room temperature. Inset: emission image of complex 1 in pure acetonitrile solution and $\mathrm{CH}_{3} \mathrm{CN}$-water mixture $\left(f_{\mathrm{w}}=90 \%\right)$ under 365 nm UV illumination.
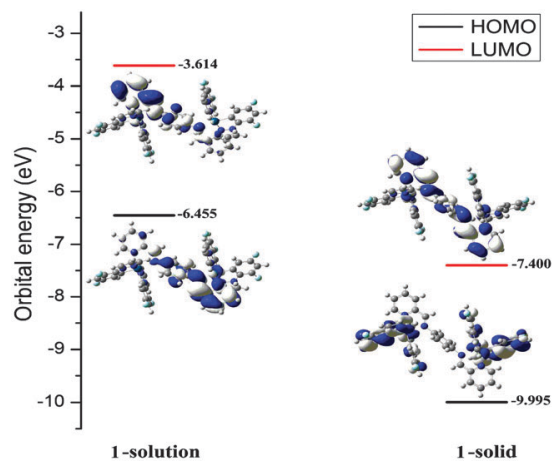

Fig. 2 Molecular orbital diagrams, HOMO and LUMO energies for complex 1 at its $S_{0}$ optimized geometries in solution state and solid state.

orbital (LUMO) mainly reside on the Schiff base bridging ligand. In essence, this Intra-Ligand Charge Transfer (ILCT) excited state is harmful for luminescence. ${ }^{11}$ Moreover, based on the crystallographic analysis and DFT data for $\mathbf{1}$ there are large structural distortions in the $T_{1}$ geometry compared to the $S_{0}$ geometry. These distortions induce an excited state relaxation and may result in an effective pathway for nonradiative decay, which can explain the weak emission in the solution state (Table S3, ESI $\dagger){ }^{12}$ By comparison, in the solid state, obvious Metal-toLigand Charge Transfer (MLCT) and Ligand-to-Ligand Charge Transfer (LLCT) excited states exist and these will favour more radiative processes than ILCT excited states and thereby greatly enhance the luminescence in the solid state. ${ }^{13}$

Under UV light irradiation the as-prepared powders 1 and 2 exhibit yellow and orange phosphorescence at $\lambda_{\max } 612 \mathrm{~nm}$ and $627 \mathrm{~nm}$, respectively (Fig. S3, ESI $\dagger$ ). These samples are hereafter referred to as $\mathbf{P 1}$ and $\mathbf{P 2}$. Interestingly, grinding both complexes on quartz plates (to give samples referred to as $\mathbf{G 1}$ and G2, respectively) induced a red-shift of the emission by $c a .20 \mathrm{~nm}$ to $\lambda_{\max } 635 \mathrm{~nm}$ and $648 \mathrm{~nm}$, respectively (Fig. S4 and S5, ESI $\dagger$ ), clearly visible to naked eyes. Evidently, both $\mathbf{P 1}$ and $\mathbf{P 2}$ exhibit pressure-induced piezochromic behaviour. To investigate the reversibility of this behaviour, G1 and $\mathbf{G 2}$ were exposed to $\mathrm{CH}_{2} \mathrm{Cl}_{2}$ solvent vapour which caused the emission spectra to revert to the original spectra of $\mathbf{P 1}$ and $\mathbf{P 2}$ within a few seconds (Fig. S5, ESI $\dagger$ ), demonstrating a vapochromic effect because of vapour-induced recrystallization. ${ }^{14}$

By exploiting the piezochromic and vapochromic responses of complex 2, a re-writable phosphorescence data recording device has been constructed (Fig. 3). The procedure is as follows. When the asprepared ground powder $\mathbf{G} 2$ is carefully spread on a filter paper using a porcelain pestle to make a thin film, it emits red light upon excitation with a UV lamp. Then a letter " $r$ " was written on the 'paper' using a 'pen' (made from a glass pipette) with $\mathrm{CH}_{2} \mathrm{Cl}_{2}$ vapour as the 'ink', and an orange-emitting symbol with large colour contrast is observed. Erasing the letter " $\mathrm{r}$ " by grinding reinstalls the original red background. A new letter "I" can now be written on the paper and erased using the same method described above. The writing and erasing processes can be repeated many times.

To understand the origin of this reversible piezochromic behaviour of complexes 1 and 2, NMR spectroscopy, X-ray 


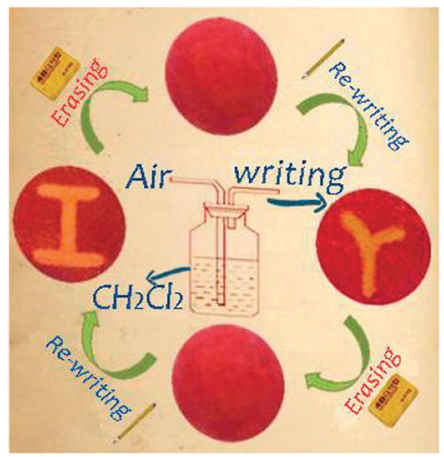

Fig. 3 A phosphorescence re-writable data recording device based on mechanochromic and vapochromic phosphorescence of complex $\mathbf{2}$.

crystallographic analysis, time-resolved emission decay, powder X-ray diffraction (PXRD) combined with differential scanning calorimetry (DSC) studies were performed. ${ }^{1} \mathrm{H}$ NMR spectra showed similar peak shapes and chemical shift values for both samples $\mathbf{P 2}$ and G2 (Fig. S11, ESI $\dagger$ ). This result proves that no chemical reaction occurs during the grinding process. Therefore, we conclude that piezochromic behaviour is caused by physical processes, such as changing the intermolecular interactions and/or the mode of the molecular packing.

The single crystal packing structure of complex 1 reveals an obvious intermolecular $\pi-\pi$ interaction between the neighbouring pyrazole rings which induces a face-to-face aggregation (Fig. 4). This packing might be easily modified by external mechanical pressure resulting in increased molecular conjugation, thereby facilitating a red-shift of the PL spectrum. ${ }^{15}$ The excited-state lifetimes $(\tau)$ for the as-synthesized samples $\mathbf{P 1}(0.18 \mu \mathrm{s})$ and $\mathbf{P 2}$ $(0.17 \mu \mathrm{s})$ are significantly different from those of ground samples G1 $(0.22 \mu \mathrm{s})$ and $\mathbf{G 2}(0.20 \mu \mathrm{s})$ : the grinding results in an increase of $\tau$, indicating that the mode of solid-state molecular packing and/or the intermolecular interactions are altered after grinding which weakens the intermolecular $\pi-\pi$ interactions ${ }^{16}$ For $\mathbf{G 1}$ and $\mathbf{G} 2$ the excited-state lifetimes $(\tau)$ of heated or $\mathrm{CH}_{2} \mathrm{Cl}_{2}$ fumed samples and as-synthesized samples are almost identical (Table S2, ESI $\dagger$ ) confirming that they are the same species.

The powder X-ray diffraction (PXRD) patterns (Fig. 5a and b) are consistent with the single-crystal diffraction data. The intense and sharp reflection peaks demonstrate that $\mathbf{P 1}$ and $\mathbf{P} 2$ are well-ordered aggregates. In contrast, the ground samples $\mathbf{G 1}$ and $\mathbf{G} \mathbf{2}$ show very weak and broad diffraction signals, indicating their amorphous states. After heating or exposing the ground samples to $\mathrm{CH}_{2} \mathrm{Cl}_{2}$

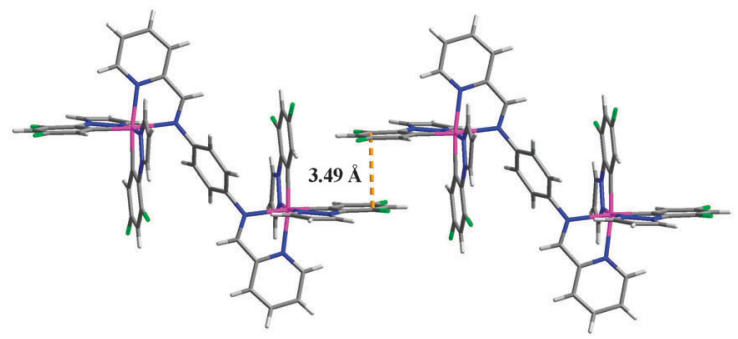

Fig. 4 Interaction between two molecules of complex 1 in the $X$-ray crystal structure. The $\mathrm{PF}_{6}{ }^{-}$anions are omitted for clarity. some sharp diffraction peaks reappeared. Thus, piezochromic reversibility for complexes $\mathbf{1}$ and $\mathbf{2}$ is ascribed to crystallization and amorphization upon the grinding-heating (or vapour exposure) process. Small differences in the patterns between $\mathbf{P}$ and Heated $\mathbf{G}$ and Fumed $\mathbf{G}$ samples could be ascribed to different aggregated states after treatment. In addition, upon heating G1 and G2 to $350{ }^{\circ} \mathrm{C}$, the DSC traces exhibited a clear broad exothermic recrystallization peak at $c a .280{ }^{\circ} \mathrm{C}$ and $290{ }^{\circ} \mathrm{C}$, respectively (Fig. $5 \mathrm{c}$ and d). This peak is at a similar temperature at which thermal recrystallization begins to take place. When G1 and G2 were heated at $290{ }^{\circ} \mathrm{C}$ for $1 \mathrm{~min}$, the emission colours also reverted to their original colours. Upon further grinding of the heated samples again, a highly reproducible red-shift of the emission again occurred. This piezochromic behaviour of complexes $\mathbf{1}$ and 2 was shown to be reversible for many cycles (Fig. 5e and f).

In summary, two new AIE-active cationic dinuclear Ir(III) complexes which show highly reversible piezochromic phosphorescence are reported. It is proposed that the flexible imine units of the Schiff base bridging ligand play an important role in achieving AIE, while the phenylpyrazole groups lead to simultaneous piezochromism. Developing new Ir(III) complexes with versatile and flexible bridging ligands holds great promise as a new strategy to achieve highly efficient piezochromic and AIE phosphorescence materials in the future.

The work in China was funded by NSFC (No. 51203017, No. 51473028 and No. 21303012), the key scientific and technological project of Jilin province (20150204011GX). EPSRC funded the work in Durham.
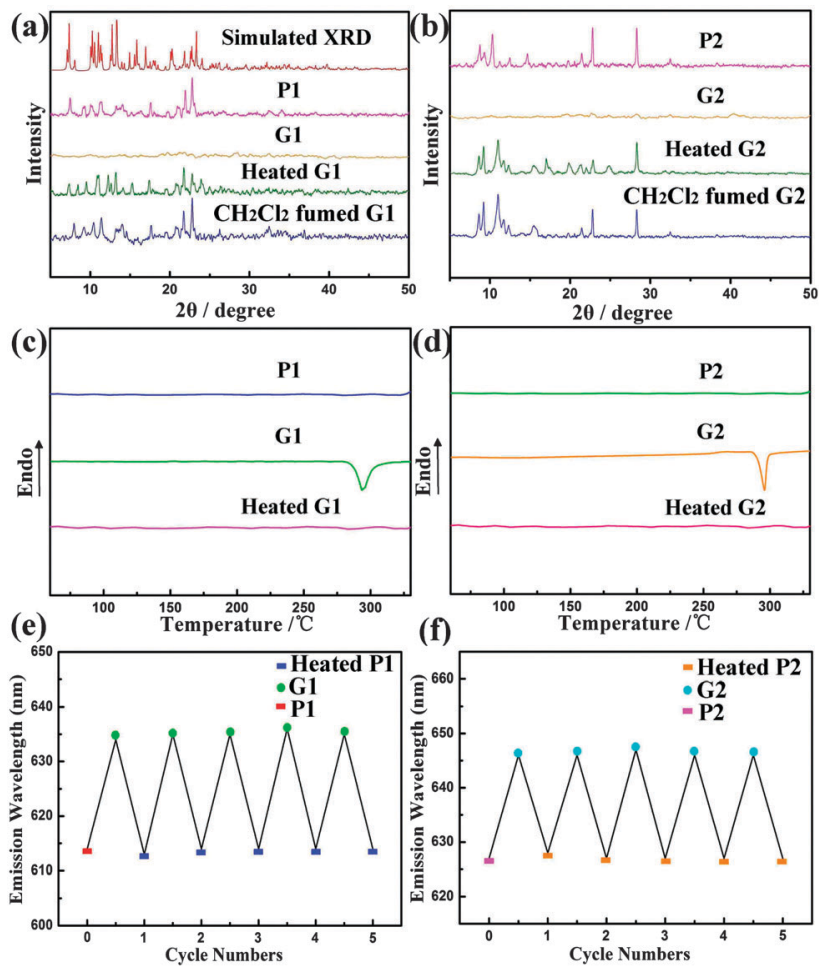

Fig. 5 Powder X-ray diffraction patterns (a) and (b) and the DSC traces (c) and (d) of the corresponding samples; repeated cycles of the piezochromism (e) and (f). 


\section{Notes and references}

1 (a) M. A. Baldo, D. F. O’Brien, Y. You, A. Shoustikov, S. Sibley, M. E. Thompson and S. R. Forrest, Nature, 1998, 395, 151; (b) S. Lamansky, P. Djurovich, D. Murphy, F. Abdel-Razzaq, H. E. Lee, C. Adachi, P. E. Burrows, S. R. Forrest and M. E. Thompson, J. Am. Chem. Soc., 2001, 123, 4304; (c) M. Mydlak, C. Bizzarri, D. Hartmann, W. Sarfert, G. Schmid and L. De Cola, Adv. Funct. Mater., 2010, 20, 1812; (d) H. Sasabe, J.-i. Takamatsu, T. Motoyama, S. Watanabe, G. Wagenblast, N. Langer, O. Molt, E. Fuchs, C. Lennartz and J. Kido, Adv. Mater., 2010, 22, 5003; (e) V. W.-W. Yam and K. M.-C. Wong, Chem. Commun., 2011, 47, 11579; $(f)$ S. Ladouceur and E. Zysman-Colman, Eur. J. Inorg. Chem., 2013, 2895; $(g)$ A. M. Bünzli, E. C. Constable, C. E. Housecroft, A. Prescimone, J. A. Zampese, G. Longo, L. Gil-Escrig, A. Pertegás and H. J. Bolink, Chem. Sci., 2015, 6, 2843; (h) A. Auffrant, A. Barbieri, F. Barigelletti, J. Lacour, P. Mobian, J.-P. Collin, J.-P. Sauvage and B. Ventura, Inorg. Chem., 2007, 46, 6911.

2 (a) M. Burnworth, L. Tang, J. R. Kumpfer, A. J. Duncan, F. L. Beyer, G. L. Fiore, S. J. Rowan and C. Weder, Nature, 2011, 472, 334; (b) M. M. Caruso, D. A. Davis, Q. Shen, S. A. Odom, N. R. Sottos, S. R. White and J. S. Moore, Chem. Rev., 2009, 109, 5755; (c) Z. Chi, X. Zhang, B. Xu, X. Zhou, C. Ma, Y. Zhang, S. Liu and J. Xu, Chem. Soc. Rev., 2012, 41, 3878; (d) Y. Dong, B. Xu, J. Zhang, X. Tan, L. Wang, J. Chen, H. Lv, S. Wen, B. Li, L. Ye, B. Zou and W. Tian, Angew. Chem., Int. Ed., 2012, 51, 10782; (e) A. Kishimura, T. Yamashita, K. Yamaguchi and T. Aida, Nat. Mater., 2005, 4, 546; $(f)$ W. Z. Yuan, Y. Tan, Y. Gong, P. Lu, J. W. Y. Lam, X. Y. Shen, C. Feng, H. H. Y. Sung, Y. Lu, I. D. Williams, J. Z. Sun, Y. Zhang and B. Z. Tang, Adv. Mater., 2013, 25, 2837.

3 (a) H. Bi, D. Chen, D. Li, Y. Yuan, D. Xia, Z. Zhang, H. Zhang and Y. Wang, Chem. Commun., 2011, 47, 4135; (b) C. Y. K. Chan, Z. Zhao, J. W. Y. Lam, J. Liu, S. Chen, P. Lu, F. Mahtab, X. Chen, H. H. Y. Sung, H. S. Kwok, Y. Ma, I. D. Williams, K. S. Wong and B. Z. Tang, Adv. Funct. Mater., 2012, 22, 378; (c) Y. Dong, J. Zhang, X. Tan, L. Wang, J. Chen, B. Li, L. Ye, B. Xu, B. Zou and W. Tian, J. Mater. Chem. C, 2013, 1, 7554; (d) Y. Sagara and T. Kato, Angew. Chem., Int. Ed., 2008, 47, 5175; (e) S. Xu, T. Liu, Y. Mu, Y. F. Wang, Z. Chi, C. C. Lo, S. Liu, Y. Zhang, A. Lien and J. Xu, Angew. Chem., Int. Ed., 2015, 54, 874; $(f)$ S. J. Yoon, J. W. Chung, J. Gierschner, K. S. Kim, M. G. Choi, D. Kim and S. Y. Park, J. Am. Chem. Soc., 2010, 132, 13675; $(g)$ X. Zhang, Z. Chi, Y. Zhang, S. Liu and J. Xu, J. Mater. Chem. C, 2013, 1, 3376.
4 (a) B. Xu, J. He, Y. Mu, Q. Zhu, S. Wu, Y. Wang, Y. Zhang, C. Jin, C. Lo, Z. Chi, A. Lien, S. Liua and J. Xu, Chem. Sci., 2015, 6, 3236; (b) B. Xu, M. Xie, J. He, B. Xu, Z. Chi, W. Tian, L. Jiang, F. Zhao, S. Liu, Y. Zhang, Z. Xu and J. Xu, Chem. Commun., 2013, 49, 273.

5 J. Luo, Z. Xie, J. W. Lam, L. Cheng, H. Chen, C. Qiu, H. S. Kwok, X. Zhan, Y. Liu, D. Zhu and B. Z. Tang, Chem. Commun., 2001, 1740.

6 (a) T. Butler, W. A. Morris, J. Samonina-Kosicka and C. L. Fraser, Chem. Commun., 2015, 51, 3359; (b) Q. Lu, X. Li, J. Li, Z. Yang, B. Xu, Z. Chi, J. Xu and Y. Zhang, J. Mater. Chem. C, 2015, 3, 1225; (c) R. Misra, T. Jadhav, B. Dhokale and S. M. Mobin, Chem. Commun., 2014, 50, 9076; (d) G. F. Zhang, H. Wang, M. P. Aldred, T. Chen, Z. Q. Chen, X. Meng and M. Q. Zhu, Chem. Mater., 2014, 26, 4433.

7 B. Xu, J. He, Y. Mu, Q. Zhu, S. Wu, Y. Wang, Y. Zhang, C. Jin, C. Lo, Z. Chi, A. Lien, S. Liua and J. Xu, Chem. Sci., 2015, 6, 3236.

8 (a) G. G. Shan, H. B. Li, J. S. Qin, D. X. Zhu, Y. Liao and Z. M. Su, Dalton Trans., 2012, 41, 9590; (b) G. G. Shan, H. B. Li, H. Z. Sun, D. X. Zhu, H. T. Cao and Z. M. Su, J. Mater. Chem. C, 2013, 1, 1440; (c) G. G. Shan, H. B. Li, H. T. Cao, D. X. Zhu, P. Li, Z. M. Su and Y. Liao, Chem. Commun., 2012, 48, 2000; (d) G. G. Shan, H. B. Li, D. X. Zhu, Z. M. Su and Y. Liao, J. Mater. Chem. C, 2012, 22, 12736.

9 (a) L. Sacconi, Coord. Chem. Rev., 1966, 1, 126; (b) M. Nath and S. Goyal, Main Group Met. Chem., 1996, 19, 75; (c) M. Nath and P. K. Saini, Dalton Trans., 2011, 40, 7077.

10 S. P. Anthony, ChemPlusChem, 2012, 77, 518.

11 (a) S. Lamansky, P. Djurovich, D. Murphy, F. Abdel-Razzaq, R. Kwong, I. Tsyba, M. Bortz, B. Mui, R. Bau and M. E. Thompson, Inorg. Chem., 2001, 40, 1704; (b) C. H. Shin, J. O. Huh, S. J. Baek, S. K. Kim, M. H. Lee and Y. Do, Eur. J. Inorg. Chem., 2010, 3642 .

12 J. Mei, Y. Hong, J. W. Y. Lam, A. Qin, Y. Tang and B. Z. Tang, Adv. Mater., 2014, 26, 5429.

13 K. Huang, H. Wu, M. Shi, F. Li, T. Yi and C. Huang, Chem. Commun., $2009,1243$.

14 J. Wang, J. Mei, R. Hu, J. Z. Sun, A. Qin and B. Z. Tang, J. Am. Chem. Soc., 2012, 134, 9956.

15 X. Zhang, Z. Chi, H. Li, B. Xu, X. Li, W. Zhou, S. Liu, Y. Zhang and J. Xu, Chem. - Asian J., 2011, 6, 808.

16 S. Mizukami, H. Houjou, K. Sugaya, E. Koyama, H. Tokuhisa, T. Sasaki and M. Kanesato, Chem. Mater., 2005, 17, 50. 